\title{
A contribuição das TICs para aumentar a credibilidade da imagem do destino. Estudo exploratório para o segmento de turismo acadêmico
}

\author{
Jakson Renner Rodrigues Soares \\ Universidade da Coruña \\ jaksonrenner@yahoo.com.br
}

Recibido: 10-07-2015

Aceptado: 16-07-2015

Keywords: Academic Tourism; image of tourist destinations; information sources; Santiago de Compostela; credibility of the information; tourist behavior.

\section{ABSTRACT}

The contribution of TICs to enhance the credibility of destination image. An exploratory study for academic tourism segment. The existence of international students is an increasingly evident situation in the Galician universities. Due to the competitiveness not only between destinations, but also between universities, it is necessary to understand what are the aspects that influence the student's choice. Moreover, knowing how we can influence the decision of that tourist is a vital point for competitiveness. This paper tries to define the international student mobility as a tourist segment, in addition to proposing variables that make up your image. The survey was conducted based on exploratory qualitative perspective. We identify a set of characteristics of the image formation process. Affective and cognitive aspects that are considered by the academic tourists and influence their destination choice behavior. We obtain these results using methods of collection as qualitative interviews and content analysis, respectively. Among the findings, we highlight the importance given to organic information registered by respondents, which can and should be considered by the stakeholder of a destination that works with this tourist segment.
Palauras-chave: Turismo acadêmico; imagem dos destinos turísticos; fontes de informação; Santiago de Compostela; credibilidade da informação; comportamento do turista.

\section{RESUMO}

A existência de estudantes internacionais em Galicia é uma situação cada vez mais evidente nas universidades galegas. Devido à competitividade existente não só entre destinos, mas também entre universidades, entender quais são os aspectos que influenciam na eleição do estudante, e saber como podemos influenciar na decisão desse turista é um ponto vital para a competitividade destes dois entes. Neste trabalho buscamos definir a mobilidade estudantil internacional como segmento turístico, além de propor variáveis que conformam a sua imagem. A pesquisa foi realizada segundo uma óptica qualitativa exploratória. Com ela se logrou identificar um conjunto de características do processo de formação da imagem. Aspectos afetivos e cognitivos que são considerados pelo turista acadêmico e que influem no seu comportamento de escolha do destino. Para chegar a esses resultados empiricamente, utilizou-se como métodos de coleta e análises dos dados a entrevista qualitativa e a análise de conteúdo, respectivamente. Dentre os resultados encontrados, cabe destacar a importância dada às informações orgânicas consultadas pelos entrevistados, que podem e devem ser consideradas pelos 
stakeholders de um destino que

trabalhe com este segmento turístico.

\section{INTRODUÇÃO}

As viagens por motivos de estudos são um fenômeno que adquiriu muita importância para o turismo em Espanha nos últimos anos. A imagem turística destaca pelo seu relevante papel dentro do processo de escolha do destino, ademais, é considerada tão importante como as próprias particulares do destino. Relacionado a isso, diversos são os atributos avaliados pelo turista que influem na imagem de um lugar, entre eles se evidencia a importância das informações que recibidas sobre o destino.

Existe uma escassa bibliografia sobre o termo turismo acadêmico, com isso, torna-se importante que a academia trabalhe essa nova proposta de segmento turístico, para conhecer suas particularidades. Para isso, deve-se considerar que a imagem de um destino varia de acordo com quem o está vendo, e entender que ela é uma criação mental desenvolvida pelo turista potencial baseando-se em impressões selecionadas entre um conjunto total de impressões (Fakeye e Crompton, 1991). Finalmetne, a relação entre as fontes de informação e a imagem demonstra que as primeiras influem na segunda (Baloglu e McCleary, 1999; Gartner, 1993). Por esta tendência e buscando compreender o fenômeno da mobilidade estudantil internacional em Galícia, este trabalho objetiva conhecer os atributos que conformam a imagem do destino (Santiago de Compostela) para estudantes internacionais (brasileiros), considerando essa mobilidade como turismo acadêmico.

O artigo está organizado em sete seções. Nessa primeira seção, encontramos a introdução do tema a ser estudado e o seu principal objetivo. Com a segunda seção aprofundamos na teoria da imagem que vai guiar o trabalho exploratório para a delimitação desse segmento turístico. na terceira seção se propõe uma definição para o turismo acadêmico, apoiando-se em teorias anteriormente consultadas na literatura turística. Na quarta apresenta-se o detalhamento metodológico seguido para a realização do trabalho, e na quinta seção são apresentados os resultados encontrados. As considerações finais podem ser consultadas na sexta seção do artigo. Finalmente, as referências consultadas para embasar esse trabalho de investigação estão na sétima e última seção.

\section{A IMAGEM DOS DESTINOS TURÍSTICOS}

A decisão de compra por parte do consumidor turista guia-se por uma cautela maior que para outros bens de consumo. A imagem de um destino concreto é um atributo decisivo na eleição das férias (OMT, 2010; Baloglu e Mccleary, 1999), onde pode servir de grande apoio, quando é positiva, ou também como um grande obstáculo quando seja negativa (Azevedo, Magalhães e Pereira, 2010). Portanto, devido à grande concorrência no turismo, faz-se necessário conhecer como se forma a imagem dos destinos turísticos para poder trabalhar os seus atributos de maneira mais atrativa (Soares, 2015). Neste sentido, segundo Azevedo, Magalhães e Pereira (2010) a imagem funciona como uma ponte entre o consumidor e o produto, e nela se reflete a personalização, identificação e diferenciação do destino.

Segundo Baloglu e McCleary (1999), a imagem é um valioso conceito para entender a seleção de um destino pelos turistas. E deve-se considerar que ele não examina os atributos do destino de forma isolada. Isso faz com que o destino seja compreendido como um mix de produtos -formado pelo lugar em si e também pelo conjunto de atrativos físicos-, e de serviços -eventos, hospedagem, restaurantes, bibliotecas- (Machado, 2010; Pawlowska e 
Martínez, 2009) que irão influenciar na decisão do turista. Destarte, é de suma importância estudar a imagem dos destinos, pelo feito dela ser um dos fatores que mais importam para a escolha (Echtner e Ritchie, 1991; Valls, 1992; Acerenza, 2002; Bignami, 2002) além de poder servir como aspecto chave para a sua diferenciação (Kotler et al., 2005). Mas é necessário destacar que ainda que o marketing seja uma ferramenta importante para o processo de formação da imagem dos destinos, as informações consideradas mais fiáveis e influentes são as que têm carácter mais pessoal, como as transmitidas boca a boca. Estas informações estarão filtradas de percepções individuais do sujeito que viveu a experiência (Van Manen, 2003) no destino.

Além disso, segundo Salgado, Godinho e Milheiro (2012), as Tecnologias da Informação e da Comunicação TICs estão sendo cada vez mais utilizadas em turismo, e contribuem definitivamente para a imagem e sustentabilidade do destino. Assim sendo, o uso de páginas que funcionem como agregadores de informação tem se utilizado como uma maneira de apresentar as singularidades do destino. Portanto, a imagem do lugar tem a possibilidade de ser evidenciada no mercado turístico, não só através dos esforços de marketing, mas também através do próprio turista.

Ponderando a imagem dos destinos como principal fator para a atração de turistas a um determinado lugar, considera-se também que ela muda a partir da visita e da experiência alí vivida (Kim, 2014). Deste modo, cabe destacar que é necessário avaliar aspectos como satisfação e lealdade, dado que são fatores capazes de determinar o desenvolvimento de uma área turística em relação a outra (Janeiro e Tagliorette, [2007 ou 2008]; Mariani, Barboza e Arruda, 2012). Isto porque, segundo Souza et al. (2014), uma imagem favorável serve não só como um indutor do desejo de visitar um país, senão também como um fator de atração para o turista repetir novamente.

\section{UMA APROXIMAÇÃO À DEFINIÇÃO DE TURISMO ACADÊMICO}

Este pesquisa girou ao redor do turismo acadêmico, segmento pouco estudado pela academia e muito explorado pelo marketing (Pawlowska, 2011). Acertadamente Pawlowska foi quem mais se aproximou a uma definição para essa modalidade como turismo, porém, entendemos que ela pode ser melhorada. Destarte, buscamos eliminar possiveis equívocos e adaptá-la ao conceito de turismo proposto pela OMT (2010), desenvolvendo a definição de Pawlowska e Martínez (2009) considerando três aspectos: atividades no destino, duração da estadia e perfil do turista.

Portanto, quando nos referimos a turismo acadêmico estamos tratando de "todas as viagens que realizan as pessoas, com estâncias de duração inferior a um ano e superior a um día, levadas a cabo nos centros de educación superior en lugares distintos ao do seu contorno habitual, com a finalidade de realizar cursos relacionados com uma carreira acadêmica e/ou atender a cursos específicos organizados por estes centros" (Soares, 2015).

Não obstante, para que haja turismo acadêmico, os destinos (oferta) devem ter características capazes de atrair os turistas acadêmicos (demanda). Segundo Leiva (2012), o turista que realiza viagens por motivos de estudos, se bem tem como motivação principal a oferta educacional-acadêmica, também possui outros motivos secundários que não estão relacionados com a motivação acadêmica. O que se pode identificar é que são também aspectos lúdicos, conhecimentos de novos lugares, culturas e gente os que motivam de maneira importante os turistas acadêmicos (García e Collado, 2007; MTUR, 2008; Leiva, 2012). 
O que se entende a partir da problemática deste termo é que são muito variadas as motivaçãos que levam os estudantes acadêmicos a realizar a sua viagem, sendo influenciados não só por aspectos acadêmicos (bibliotecas, residências universitárias, serviços universitários) senão também por atributos turísticos do destino (transporte, restauração, alojamentos...) (Pawlowska e Martínez, 2009; Pawlowska, 2011). Não só isso, deve-se considerar também a afirmação de Baloglu e McCleary (1999) que indicam que a segmentação deve ser tal para lograr o interesse de diferentes grupos, neste caso, o futuro turista estudante. Além disso, segundo Gândara (2008) a imagem do destino deve guardar relação com a realidade, para que a satisfação com este seja atingida. E não só isso, segundo Crespi Vallbona e Domínguez Pérez (2013), os destinos projetam suas imagens ao exterior para atrair os turistas, onde estas refletem as suas especificidades próprias para poder competir no mundo global.

Em relação com as atividades realizadas no destino, entende-se que a grande diferença capaz de caracterizar o perfil do turista acadêmico com relação ao de outros turismos relacionados com viagens de estudo é que, para que seja considerado turismo acadêmico, a atividade principal terá relação primordial com a capacitação acadêmica do indivíduo, isto é, com a sua carreira universitária (Pawlowska e Martínez, 2009; Pawlowska, 2011; Leiva, 2012).

\section{METODOLOGIA}

O estudo realizou-se com uma investigação qualitativa, para poder aprofundar em matizes, contradições e anédotas com a finalidade de entender as peculiaridades dos indivíduos objeto do estudo (Del Rincón, Arnal e Latorre, 1995). Além disso, essa abordagem não se preocupa em quantificar, mas sim em compreender e explicar as relações sociais, depositárias de crenças, valores, atitudes e hábitos (Couceiro e Paiva, 2010) relacionados, neste caso, com a imagem de um destino de turismo acadêmico.

Com um carácter mais bem exploratório, buscou-se com esta pesquisa identificar as variáveis que influenciam a escolha do destino, partindo da suposição de que a recolhida de diversos tipos de dados pode garantir um melhor entendimento do problema de pesquisa. Em definitiva, Samaja (2012) afirma que nada se pode esperar da análise de variáveis, referindo-se aos estudos puramente quantitativos, quando só se fala do seu funcionamento e forma de operação, sem compreender como elas surgiram.

Portanto, o que se buscava era permitir que a informação emanasse do próprio campo, buscando mais aproximação à realidade do fenômeno turístico (Sancho Perez et al., 2001). Isto é, como o objeto de estudo desta pesquisa é o turismo, buscou-se com esta análise interpretar o fato e entender tal fenômeno, proporcionando uma visão da realidade, das percepções, das experiências, dos valores, das crenças e da construção de sentido dos sujeitos participantes da pesquisa, quer dizer, o turista.

A recolhida de dados foi através de entrevistas qualitativas com roteiro semiestruturado, visando identificar as características e dimensões do turismo acadêmico, além dos fatores que conformam a imagem destes destinos. Creswell e Clark (2013) sustentam que é necessária uma fase exploratória qualitativa para poder descobrir as questões, variáveis e teorias capazes de caracterizar um estudo, neste caso, a imagem dos destinos de turismo acadêmico. Recorreu-se à revisão bibliográfica para o desenho do roteiro das entrevistas e utilizou-se a análise do conteúdo na análise dos dados recolhidos. 
O objetivo final do presente trabalho é investigar a percepção do turista acadêmico brasileiro a cerca das relações entre a imagem e a satisfação com Galicia. Em consequência, este trabalho objetiva os seguintes pontos:

1. Compreender o processo de formação da imagem para o destino de turismo acadêmico através das entrevistas qualitativas com roteiro semiestruturado.

2. Identificar atributos da imagem (tanto afetivos como cognitivos) que podem influenciar ao turista acadêmico na escolha do destino.

\subsection{Técnica de recolhida dos dados}

Com a entrevista qualitativa utilizam-se perguntas abertas que buscam a espontaneidade da contestação nas respostas (Valles, 2014). Com ela os indivíduos entrevistados podem descrever livremente as suas impressões e crenças sobre o destino, e além disso, com esta técnica dispõe-se da oportunidade de captar "os silêncios -os não ditos-, o sobre-entendido e o oculto nos discursos" (García Espinoza, 2010).

O uso da técnica não estruturada en turismo consiste na recolhida de informação através de uma relação de perguntas propostas pelo entrevistador (Andrade Suárez, 2010), onde o sujeito responde a questões desenhadas em função dos objetivos do estudo. Esta técnica explora um assunto a partir da busca de informações, percepções e experiências dos informantes, para assim analisá-las e apresentá-las de forma estruturada. Huang e Chai (2011) asseveram que as perguntas devem ser elaboradas de tal maneira que os sujeitos possam exteriorizar pensamentos livres, e sentimentos, sobre o que lhes está sendo questionado. Portanto, com ese tipo de entrevista, e segundo (Couceiro e Paiva, 2010), devese buscar contribuir à compreensão da realidade a partir de valores simbólicos e subjetivos do grupo, onde cada indivíduo pode dar uma interpretação diferente sobre a realidade vivida (Poupart, 2008). Com tudo, consideraram-se as quatro vantagens propostas por este último autor, na escolha dessa entrevista como técnica de recolhida de dados:

a) Baseia-se na realidade do entrevistado, permitindo que se expresse livremente sobre os temas da pesquisa.

b) Possibilita a aparição de novas dimensões que inicialmente puderam não ser consideradas pelo pesquisador no corpus do seu trabalho.

c) Busca a saturação da informação dada pelo entrevistado.

d) Permite uma melhor exposição da experiência, graças à sua flexibilidade.

\subsection{Técnica de análise dos dados}

Utilizou-se a análise do conteúdo (AC) como técnica para a análise dos dados encontrados nesse fenômeno turístico, pois segundo Bauer (2002), é um método de análise de texto desenvolvido dentro das ciências sociais. A AC "é considerada uma técnica para o tratamento de dados que visa identificar o que está sendo dito a respeito de determinado tema" (Vergara, 2005, p. 15).

Este método foi originalmente detalhado pela francessa Laurence Bardin, mas neste estudo trabalhou-se desde um ponto de vista menos clássico. Navarro e Díaz (1994) afirmam que para isso se deve contemplar a $\mathrm{AC}$ em termos instrumentais, além de se orientar pelo rigor na utilização desta análise com a finalidade de ultrapassar as dúvidas levantadas. Os autores propõem uma análise onde o fenômeno da significação tem que ser entendido como uma realidade da subjetividade individual, neste caso, há que aplicar uma análise desde um critério de homogeneidade semântica. Assim, na apresentação dos resultados, segundo Rego e Pinzani (2013), devem apresentar-se de forma narrativa os fragmentos considerados mais 
significativos de cada uma destas entrevistas. Entretanto, segundo Navarro e Díaz (1994), apesar da variedade de métodos e técnicas de se realizar AC, o procedimento que se pode considerar padrão é a codificação.

Cabe destacar o que Bauer (2002) pontualiza sobre a validez desse método. Ele explica que a AC "é uma técnica para produzir inferências de um texto focal para seu contexto social de maneira objetivada", referindo-se aos procedimentos explícitos e replicáveis adotados na análise dos dados. Além disso, o autor cita ainda que essa validez será julgada pela "sua fundamentação nos materiais pesquisados e sua congruência com a teoria do pesquisador, e à luz de seu objetivo de pesquisa" (Bauer, 2002, p. 191).

\section{RESULTADOS}

O primeiro passo dado neste processo foi a leitura flutuante, a qual consta das primeiras explorações dos documentos utilizados na recolhida dos dados, chegando à determinação de categorias. Finalmente, optou-se por uma interpretação dos resultados por meio do emparelhamento, que, segundo Vergara (2005, p. 19), é a "associação dos resultados ao referêncial teórico utilizado".

Como método de recolhida de dados inicial (pré-entrevista), realizou-se a pesquisa bibliográfica relacionada com o tema em questão, o turismo acadêmico, e só depois se efetuaram as entrevistas individuais. Decidiu-se entrevistar a uma parte dos turistas acadêmicos em Galicia, concretamente na cidade de Santiago de Compostela. Para selecionar os indivíduos, buscou-se recolher a visão de estudantes que levassen diferentes períodos no destino (meses/semestre/ano), além de procurar a participação de ambos os sexos, abarcando assim um máximo de vivências diferentes. $\mathrm{Na}$ tabela que segue se encontram os conceitos, autores e temáticas utilizados no desenho do roteiro da entrevista.

Tabela 1: Conceitos básicos utilizados para organizar o roteiro da entrevista

\begin{tabular}{|l|c|c|}
\hline Conceito & Autor & Temática \\
\hline $\begin{array}{l}\text { As características sociais do } \\
\text { individuo são determinantes do } \\
\text { seu comportamento }\end{array}$ & Schiffman e Kanuk (2000) & $\begin{array}{c}\text { Dados sociodemográficos } \\
\text { dos estudantes }\end{array}$ \\
\hline $\begin{array}{l}\text { O consumidor atua segundo } \\
\text { influxos da imagem que tem } \\
\text { sobre o destino }\end{array}$ & Chon (1991) & $\begin{array}{c}\text { A eleição do destino de } \\
\text { turismo acadêmico }\end{array}$ \\
\hline $\begin{array}{l}\text { A imagem que se forma na } \\
\text { mente do potencial turista } \\
\text { provém tanto de materiais } \\
\text { promocionais como da opinião } \\
\text { de outras pessoas en geral }\end{array}$ & Echtner e Ritchie (1991) & $\begin{array}{c}\text { Imagem orgânica e } \\
\text { induzida }\end{array}$ \\
\hline $\begin{array}{l}\text { A visita ao destino é uma fonte } \\
\text { mais de informação, e forma-se } \\
\text { apartir dos conhecimentos } \\
\text { adquiridos baseados na } \\
\text { experiência de anteriores } \\
\text { viagens ao destino }\end{array}$ & Gartner (1993) & $\begin{array}{c}\text { A imagem do destino } \\
\text { antes e depois da } \\
\text { experiência }\end{array}$ \\
\hline
\end{tabular}

Fonte: Elaboração própria.

Para o tratamento das entrevistas utilizaram-se as seguintes etapas metodológicas: 
a) Recepção

b) Codificação

c) Em caso de que fosse necessário, tornava-se a contatar com o entrevistado ou entrevistada para que pudesse oferecer mais informação sobre alguma questão.

O perfil dos entrevistados está destacado na tabela seguinte e estão identificados por um código alfanumérico para garantir o anonimato das pessoas que colaboraram com esta pesquisa.

Tabela 2: Perfil socio-demográfico das pessoas entrevistadas

\begin{tabular}{|c|c|c|c|c|c|}
\hline Código & Sexo & Idade & Origem & Curso no destino & Duração da estadia \\
\hline E1 & Mulher & 22 anos & São Paulo & Ciências Políticas* & Um quatrimestre \\
\hline E2 & Homem & 27 anos & Fortaleza & $\begin{array}{l}\text { Mestrado em } \\
\text { Turismo }\end{array}$ & $\begin{array}{l}\text { Um curso } \\
\text { acadêmico completo }\end{array}$ \\
\hline E3 & Mulher & 24 anos & Fortaleza & $\begin{array}{l}\text { Mestrado em } \\
\text { educação, gênero e } \\
\text { igualdade }\end{array}$ & $\begin{array}{l}\text { Um curso } \\
\text { acadêmico completo }\end{array}$ \\
\hline E4 & Mulher & 29 anos & Fortaleza & Psicologia* & $\begin{array}{l}\text { Mais de um curso } \\
\text { acadêmico (não } \\
\text { seguidos) }\end{array}$ \\
\hline E5 & Homem & 34 anos & São Paulo & Curso de Galego & Um quatrimestre \\
\hline E6 & Homem & 22 anos & Salvador & $\begin{array}{l}\text { Ciências Sociais } \\
\text { Aplicadas }\end{array}$ & $\begin{array}{l}\text { Um curso } \\
\text { acadêmico completo }\end{array}$ \\
\hline E7 & Homem & 22 anos & $\begin{array}{l}\text { Rio Grande do } \\
\text { Sul }\end{array}$ & Direito* & Um quatrimestre \\
\hline E8 & Mulher & 27 anos & São Paulo & $\begin{array}{l}\text { Mestrado } \\
\text { Cooperação e } \\
\text { Desenvolvimento }\end{array}$ & $\begin{array}{l}\text { Um curso } \\
\text { acadêmico completo }\end{array}$ \\
\hline E9 & Mulher & 24 anos & Belém & Filologia Hispânica* & $\begin{array}{l}\text { Um curso } \\
\text { acadêmico completo }\end{array}$ \\
\hline
\end{tabular}

Fonte: Elaboração própria.

\section{*Estudante de Graduação}

Baseando-se na revisão da literatura, e considerando a proposta de definição desta modalidade de vivências como turismo, duas das entrevistas realizadas foram descartadas para não influenciar no momento de caracterizar a imagem do destino acadêmico, mesmo que os resultados obtidos com estas duas entrevistas não deturpavam a realidade encontrada na totalidade das outras. A eliminacão foi devido a que o tempo que estes sujeitos estiveram na cidade foi mais de um ano consecutivo, portanto, não se define a estadia como turística. 


\subsection{Apresentação dos resultados das entrevistas}

Os dados encontrados estão classificados segundo os distintos conceitos que foram tratados pelos informantes, relacionando-se as suas vivências e o contexto no destino estudado. As entrevistas estão apresentadas de uma maneira direta, dividida por tópicos temáticos. En cada bloco estão compiladas as contestações mais relevantes dos informantes. Os resultados foram divididos assim, com a finalidade de conseguir uma interpretação mais atinada destes. Realizou-se uma estratégia extensiva (Navarro e Díaz, 1994), onde se necessitou de várias entrevistas para examinar de maneira completa e precisa o fenômeno. Ademais, como se considerou o conjunto de textos como produtos de uma mesma subjetividade, estes autores afirmam que se seguiu o método agregativo.

Igual que nos estudos de Huang e Cai (2011) e Rego e Pinzani (2013), as questões foram divididas para facilitar a fluidez do raciocinio e sua compreensão por parte do entrevistado. No primeiro bloco estudou-se o porque da eleição do destino (motivaçãos, aspectos influentes). No segundo recolheram-se informações detalhadas sobre a vida do estudante na cidade (lazer e tempo livre, atividades realizadas...). No terceiro bloco tratou-se o tema da imagem prévia à realização da viagem. Nesta seção intentou-se pesquisar qual era a imagem que os estudantes brasileiros tinham da cidade antes de realizar sua estância no destino. O quarto e último bloco trata da experiência depois de realizar a viagem. Nele perguntou-se sobre as expectativas e surpresas, com a finalidade de lograr informação válida cara a medir a satisfação e a fidelização ao destino. Finalemnte, cabe destacar que a formulação das perguntas não variava segundo o informante, o que sim mudava era a intensidade das respostas e, portanto, a reformulação da questão, para conseguir informação mais rica do informante sobre a sua experiência.

\subsubsection{A eleição do lugar}

A primeira pergunta realizada a todos os sujeitos foi Porque escolhestes Santiago como destino para o teu programa de intercâmbio universitário? Por mais variadas que fossem as respostas, puderam-se encontrar aspectos presentes nas contestações que ajudaram no desenho das categorias.

O prestígio da Universidade de Santiago de Compostela, apresentou-se nos discursos. Podemos citar o que nos apunta a E2, em que o informante escolheu a cidade:

Pela história da Universidade de Santiago de Compostela, pois a Universidade tem mais de 500 anos e é uma das mais conhecidas do mundo. A partir disso comecei a investigar e encantou-me a cidade e hoje estou aqui e pretendo ficar muitos anos (E2).

Além desta entrevista, a importância da Universidade foi citada em outras, como no caso da E8, onde também encontramos que esta instituição acadêmica é um reclamo importante da cidade para o estudante estrangeiro. O sujeito entrevistado nos diz:

Como historiadora era um privilégio viver em uma cidade que forma parte da historia de Espanha e também da conquista da América Latina. Entrei em contato com a Universidade e senti que o conteúdo acadêmico era muito interessante, o que me motivou ainda mais a ter essa nova experiência profissional e pessoal na minha vida (E8).

Outro motivo presente para escolher a cidade foi: a lingua galega que, pela semelhança ao português, facilita o trabalho do estudante. A E4 nos cita que "poder apresentar a tese de doutorado em português, pela semelhança do idioma" foi um motivo 
para considerar no momento de escolher o destino do seu estudo. Da mesma forma que também o identificamos na E6 "pela proximidade do idioma", e igualmente encontramos o devandito motivo na E5, en que se escolheu Santiago de Compostela "pelo curso que venho realizar em Galicia, Galego para estrangeiros".

Do mesmo jeito que a E8, a E3 nos oferece o nível dos cursos ofertados para vir estudar en Santiago de Compostela como outra motivação. Segundo ela, na Universidade está "o único mestrado en gênero ofertado. Além disso, Galicia é uma referência nas políticas de igualdade de gênero, o que motivou bastante a minha vinda". Con estas apreciacións, e fazendo referência à revisão bibliográfica realizada no marco teórico, o estudante, quando busca um destino onde realizar a sua estadia, mede tanto caracteristicas acadêmicas, tal e como se identificou nas citações anteriores, como serviços relacionados com as características da cidade.

Isto é, encontram-se, nas entrevistas realizadas, referências a estes serviços. Como na E1, que diz que o motivo que a fez considerar este destino foi "Por (Santiago de Compostela) ser pequena e mais barata que a minha outra possibilidade, Madrid." Já a E4, relaciona que foi "o feito do custo de vida não ser tão alto comparado a cidades como Barcelona ou Madrid também ajudou muito" na eleição da cidade como destino dos seus estudos. Além disso, a E9 indica que escolheu Santiago de Compostela "por ser uma cidade bastante universitária, tendo tudo o que poderia necessitar (bibliotecas de qualidade, ônibus, cinemas, parques, festivais)". Portanto, as variáveis encontradas relacionam-se com:

i) Prestígio da Universidade.

ii) Facilidade de acesso graças à língua galega (ajuda no trabalho do estudante pela semelhança ao português).

iii) Nivel dos cursos ofertados.

iv) Características da cidade (pequena, custo de vida acessivel...) que faziam do destino um lugar atrativo para o turista estudante.

Dentro da parte relacionada com a eleição do destino pelos estudantes brasileiros, outra pergunta foi se alguém aconselhou ao estudante na hora da eleição de Santiago e, em caso afirmativo, quem foi? Entendendo a importancia das fontes de informação na formação da imagem do destino (ANDRADE SUÁREZ, 2011; Gartner, 1993), com essa pergunta também se buscava identificar a importância dada às fontes de informação orgânicas, que são aquelas oferecidas por outros indivíduos que já estuveram no destino anteriormente.

Alguns informantes contestaram que não foram aconselhados por ninguém, e voltarom a citar a importância da Universidade para escolher este destino de estudos, como por exemplo a E8, que resposde que "os programas, conteúdos e contatos prévios com a Universidade de Santiago de Compostela foram todos feitos através da internet".

E, ainda relacionado com esta, a E2 cita que "na realidade não me aconselharam, falaram-me de algumas cidades em que havia mestrados em turismo e eu escolhi Santiago de Compostela pela história da Universidade". Para esta pergunta, pôde-se identificar a presença destes aspectos apresentados nas respostas, que foram citados anteriormente na revisão bibliográfica e confirmam as informações compiladas.

A informante E4 contesta que a pessoa que a aconselhou foi sua mãe, que "ja fez o seu doutorado aqui", e também, "uma prima que estava interessada em estudar aqui motivou-me a vir". Igual que na anterior, E7, responde que foi aconselhado por "gente que já passou anos antes por aqui, estudando. Também alguns professores da minha universidade, além de uma galega que conheci de férias por Brasil". Fica claro que tanto alunos de anos 
anteriores, como se encontrou nas entrevistas citadas até agora, como outras pessoas de confiança, que já visitaram a cidade, aconselharam aos estudantes à hora de realizar sua estadia de turismo acadêmico em Santiago de Compostela. É o caso da E9, em que a informante foi animada pelo seu orientador e por outros estudantes.

Finalmente, também se deu o caso de que a universidade de origem apresentasse Santiago ao futuro estudante, como na E6. E além disso, já se esperava a partir da revisão teórica, que pessoas com certa autoridade recomendassem o destino aos futuros estudantes, como se nos disse na E5, já que quem o aconselhou foi "um professor de lingüística da minha universidade".

Desta volta, conseguiu-se identificar a seguinte categorização:

i) Universidade de origem, professores/orientadores.

ii) Familiares e amigos.

iii) Estudantes de anos anteriores.

Ainda continuando nessa temática relacionada com as fontes de informação, buscouse identificar quais podem ser as fontes consultadas pelos estudantes brasileiros. Quando perguntamos "que meios de comunicação foram consuldatos para organizar a viagem a Santiago de Compostela", recebemos respostas variadas que, em xgral, são muito semelhantes em todas as entrevistas. Podemos afirmar que quase todos os entrevistados consultaram internet para buscar informação sobre o destino objeto de estudo. Blogs, redes sociais, páginas especializadas, foram citadas nas entrevistas. Além disso, as fontes orgânicas foram também as mais consultadas pelos estudantes brasileiros.

Isto é, em geral, os grupos de referência como amigos e familiares, a universidade de origem e os estudantes de anos anteriores foram os principais meios consultados para obter informação acerca do destino. Segundo encontramos na literatura, as fontes orgânicas são mais fiáveis porque apresentam a experiência vivida no destino por alguma referência do estudante. Estas fontes não são criadas com fins publicitários e são capazes de gerar mais impacto na percepção dos indivíduos. Com tudo, ainda que com menos presença, meios criados com a finalidade comercial, como também foram encontrados no discurso dos entrevistados. Assim sendo, apresenta-se a seguinte categorização para futuramente analisar o uso das fontes de informação pelos turistas estudantes:

i) Familiares ou amigos a quem solicitei informação

ii) Familiares ou amigos a quem não solicitei informação

iii) Estudantes de anos anteriores

iv) Universidade de origem

v) Folhetos turísticos

vi) Publicidade em meios massivos (imprensa, rádio, tv)

vii) Agências de viagens

viii)Guias turísticas

ix) Internet

x) Artigos, revistas, notícias, reportagens...

xi) Feiras especializadas

\subsubsection{A vida dos estudantes brasileiros no destino}

Sabendo-se que as experiências vividas in situ são aspectos relevantes para a formação da imagem final, com este ponto tentou-se compilar informação detalhada sobre a vida do estudante na cidade: como vivia o seu lazer, quais eram atividades que realizava, lugares aos que se dirigia... Encontrou-se que os estudantes, quando estão realizando este 
tipo de estadia em um destino de turismo acadêmico, buscam levar a cabo tanto atividades acadêmicas como turísticas.

Neste caso, a E7 mostra a seguinte realidade, "normalmente marco com amigos. Saímos para comer ou jantar pela cidade. Vamos a parques, quando o tempo coopera. Vou à biblioteca. Faço fotos da cidade, que é muito linda". Não muito diferente, mas com um uso do seu tempo livre mais ligado ao lazer, encontra-se na E2, segundo o que se expõe a continuação, "tento aproveitar o que a cidade tem para oferecer, o seu lado cultural, as suas festas e a sua diversidade de culturas (pessoas) e seus espaços verdes, a catedral, museus, parques e festas".

Finalmente, o aspecto cultural da cidade é algo relevante que estes estudantes identificaram. A E9 é bastante clara em quanto a estes aspectos, pois, "viajo por Galicia. Goto de estar com os amigos. Conhecer estudantes de outros países. Visitar museus. Salas de espectáculos. Conhecer a cultura de a pé da cidade". Portanto, a categorização ficou configurada da seguinte maneira:

i) Atividades acadêmicas.

ii) Atividades culturais.

iii) Visitas a parques/jardins/zonas verdes.

iv) Serviços gastronômicos.

v) Festas populares/em apartamentos compartidos.

\subsubsection{A imagem do destino para os estudantes brasileiros}

Neste ponto, buscou-se identificar qual era a imagem que os estudantes brasileiros tinham da cidade antes de realizar a sua estância no destino. Em geral se encontrou que alguns estudantes não tinham tantas expectativas acerca do destino. Como se lê na E1, "na verdade não sabia muito o que esperar, só escutei falar bem da cidade, e busquei algumas fotos na internet. Mas de verdade não me dediquei muito a isso antes de chegar".

A antigüidade da cidade, a Universidade e o passado histórico são aspectos que estão presentes no imaginário destes estudantes. $\mathrm{Na}$ E3, pode-se ler que imaginava Santiago como "uma cidade religiosa, pequena, fria, com uma universidade antiga", da mesma maneira que na E2 se afirma que tinha "imagens de uma cidade antiga, com muitos estudantes e uma magia que nenhuma outra cidade tem".

Segundo se lê na E4, o destino representa "qualidade de vida". Mas também se pode identificar outro aspecto a que já se fez referência em outros momentos durante a análise das entrevistas, o reconhecimento da Universidade de Santiago de Compostela. Esta entrevista nos diz, "o que mais me motivou foi o interesse em poder realizar o curso. Imaginei uma estrutura acadêmica preparada para receber os alunos de fora e bastante capacitada na área de pesquisa".

Outra imagem bastante presente para estes estudantes está relacionada com o misticismo da cidade. O informante da E5 pensava que Santiago era "uma cidade mística com muitos peregrinos, um ambiente bastante religioso com poucas opções noturnas". Isto condicionou um pouco as expectativas e que fossem superadas quando chegou ao destino em que se atopou com uma importante vida noturna.

Com os dados analisados, a categorização proposta ficou da seguinte forma:

i) Cidade com ambiente estudantil.

ii) Cidade com ambiente religioso. 
iii) Cidade com ambiente cultural.

iv) Cidade com ambiente turístico.

Pode-se concluir que o destino está muito bem valorado para esses turistas estudantes, dado que a cidade para este grupo é: tranquila, turística, bonita, cultural, pequena, mística, agitada, concorrida, mágica, acolhedora, impressionante, imponente, bela e possui uma história viva. Nela, todos as características encontradas são positivas. Destarte, para o destino, esse é um aspecto muito valorável, pois se espera que no momento em que estas pessoas sejam consultadas sobre a cidade, servirão para criar uma imagem positiva dela. Isto é, estes indivíduos servirão positivamente para ratificar a imagem orgânica deste lugar.

Os componentes afetivos da imagem de Santiago para os estudantes brasileiros são positivos. Encontra-se na E5 o seguinte, "gosto muito da cidade. Eu, que na atualidade vivo em Nova York, não esperava que fosse uma cidade tão "cosmopolita" por ser tão pequena. Sinto-me muito bem na cidade, me sinto seguro, tranquilo e respeitado". Concretamente, essa resposta foi de um brasileiro natural de São Paulo que realiza o seu doutorado na cidade de Nova York. Ao entender desta pesquisa, a afirmação de que a cidade é cosmopolita proporciona um ponto de vista valioso, pois a experiência vital deste informante não está limitada a uma área concreta onde não exista convivência de culturas, senão que o entrevistado possui outros elementos comparativos como são a megalópole de São Paulo e a própria cidade de Nova York. Isto parece dar um plus na valoração do destino, ao ser definida como cosmopolita por um habitante de duas das cidades mais cosmopolitas do mundo.

Na E7 aparecem sensações de "paz, tranquilidade, segurança absoluta". Além disso, esta entrevista oferece mais informação, como o bom tratatamento que se dá aos estudantes brasileiros, como se lê, "também me impressiona o bem que somos recebidos os brasileiros. Não me estranha que haja muita gente que vem a Santiago como estudante ou turista e fica muitos anos da sua vida a viver na cidade".

Com isso, pode-se deducir que os aspectos afetivos da imagem em relação com este lugar, como destino de turismo acadêmico, são favoráveis à imagem da cidade. Assim, a categorização das sensações é:

i) Segurança.

ii) Ternura.

iii) Agitação.

iv) Vida cultural.

v) Receptividade.

As características únicas de Santiago de Compostela para o grupo entrevistado estão formadas, tanto por aspectos afetivos como cognitivos da imagem. E ademais, os informantes acreditam que a cidade é reconhecida no Brasil pelos aspectos religiosos do destino. E2 diz, "penso que a cidade é mais conhecida no Brasil como uma cidade religiosa e cultural". Para a informante da E4, "a maioria das pessoas brasileiras não tem ideia da cidade. A imagem que se tem de Espanha, como na maior parte da Europa, é de qualidade de vida e riqueza... Mas Santiago parece ser uma cidade 'religiosa', mística". Ao igual que E5 afirma que "Santiago de Compostela é considerada um centro religioso de peregrinação. Acredito que exista também uma imagem mística associada à cidade".

Assim, a categorização fica organizada da seguinte maneira:

i) Atributos tangiveis. 
ii) Ambiente lúdico.

iii) Qualidade de vida.

iv) Cosmopolitismo.

v) Religiosidade.

vi) Misticismo.

vii) Nivel acadêmico.

\subsubsection{A imagem antes e depois: expectativas e surpresas}

Tratou-se de indagar sobre as expectativas e surpresas dos estudantes brasileiros para com o destino onde realizaron a sua estância de turismo acadêmico. Isto é, as fontes de informação consultadas sobre a cidade foram realistas en quanto à sua descrição. Concregtamente a categorização será em:

i) Surpresas meteorológicas.

ii) Surpresas culturais.

iii) Surpresas acadêmicas.

iv) Surpresas relações com o residente.

Como aspectos relacionados com a fidelidade ou lealdade ao destino. Identificou-se que a categorização deve-se relacionar com revisita, recomendação e recomendação condicionada.

Finalmente, a última pergunta realizada aos estudantes brasileiros estava ligada com a satisfação destes com os atributos do lugar. Esta pergunta foi realizada para identificar se estes estudantes realmente fizeram uso dos componentes turísticos da cidade e qual é a sua impressão. Desta maneira, pôde-se também sacar conclusões de que estes atributos são avaliados positivamente pelos estudantes, e agregaram valor à imagem global da cidade.

A primeira entrevistada respondeu a sua satisfação com atributos do destino em porcentagem, isto é, para o aspecto segurança na cidade, a contestação foi $100 \%$ satisfeita. Em uma pesquisa qualitativa baseada em entrevistas, o interessante é que os entrevistados falem mais sobre a sua experiência, portanto, solicitou-se que os informantes deixassem claro em palavras, como e quanto estavam satisfeitos. Reformulou-se a pergunta para pedir que os informantes detalhassem melhor as suas experiências. E com essas mudanças, os resultados foram mais satisfatórios, dado que as respostas a partir deste momento foram mais detalhadas. Assim, pode-se considerar a seguinte categorização:

i) Segurança.

ii) Oferta culinária e gastronomia.

iii) Oferta cultural.

iv) Oferta de espaços verdes, parques e jardins.

v) Serviços turísticos.

vi) Níveis de conservação do patrimônio.

vii) Relação qualidade/preço.

En consequência, com tudo o recolhido nas entrevistas, pode-se concluir que a experiência na cidade é positiva para o turista acadêmico. E, tendo como referência a teoria de Echtner e Ritchie (1991), tanto na avaliação dos contínuos atributo como na visão holística, o destino é valorado positivamente, o que resulta em uma imagem satisfatória.

Finalmente, a partir dos resultados encontrados nesse artigo, esses são os ítems que deverão ser utilizados para desenhar uma ferramenta capaz de medir a experiência do turista em um destino de turismo acadêmico. 
Tabela 3: Variáveis para serem provadas que influem na formação da imagem do destino de turismo acadêmico

\begin{tabular}{|l|}
\hline Variáveis \\
\hline Facilidade para conseguir o visto de estudos \\
\hline $\begin{array}{l}\text { Alojamentos (residências públicas das universidades, casas de familia, } \\
\text { apartamentos compartidos...) }\end{array}$ \\
\hline Serviços universitários \\
\hline $\begin{array}{l}\text { Infraestruturas turísticas (restaurantes, bares, hotéis, facilidade de acesso ao } \\
\text { destino, centros de informação, excursões...) }\end{array}$ \\
\hline Vida noturna \\
\hline Infraestruturas gerais (aeroportos, estradas, sanidade, telecomunicações) \\
\hline Segurança, hospitalidade \\
\hline Universidades e centros educativos de formação superior \\
\hline Atrações culturais (museus, parques...) \\
\hline Aprender língua \\
\hline Conhecer a língua do destino \\
\hline Conhecer gente diferente \\
\hline Visitas turísticas \\
\hline Fontes de informação \\
\hline Fonte: Elaboração própria. \\
\hline
\end{tabular}

Fonte: Elaboração própria.

\section{CONSIDERAÇÕES FINAIS}

Com este trabalho conclui-se que os motivos que levaram à eleição de Santiago de Compostela para estudantes brasileiros realizarem suas estadias de turismo acadêmico depende de vários fatores, como podem ser: -Qualidade de vida. -Baixo custo de vida. Tamanho da cidade, pequena (abarcável). -Prestígio da universidade do destino. -Formação exclusiva na universidade destino. -Linha de pesquisa referência no seu campo de estudos. Idioma do destino - Galego = português (semelhanças da língua). - Referência de amigos que vivem no destino. -Hospitalidade.

Essas características podem ser usadas pelos stakeholders envolvidos no destino para atrair estudantes. No entanto, também é verdade que elas podem ser trabalhadas em estudos quantitativos para proporcionar uma escala de medida para a imagem de um destino de turismo acadêmico. Assim, buscar quantificar a experiência, diferentemente desta pesquisa, que teve um carácter máis bem descritivo e buscava identificar os atributos que os turistas relacionavam com essa experiência.

Em geral, os turistas acadêmicos entrevistados demostraram ser indivíduos inquietos que, quando não estavam dedicados aos estudos, destinavam boa parte do seu tempo a visitas culturais (no destino e em lugares próximos). Ademais, realizavam excursões pagas pela zona com a finalidade de conhecer mais o lugar. Portanto, cabe destacar também a importância econômica que merece ser dada a esse segmento. Deve-se encarar que este turista passa mais tempo no destino, fazendo um gasto em alimentação, transporte ou alojamento prolongado no tempo. Claro, quanto mais tempo esse turista permaneça no destino, mais possibilidade ele terá de contratar serviços como telefonia e internet, mas principalmente poderá contratar serviços turísticos, como encontramos nessas experiências.

Esse tipo de turismo também permite ao destino a possibilidade de criar um relacionamento mais estreito com o indivíduo turístico. Essa experiência, normalmente, vivese em uma etapa de grandes descubertas para o sujeito. Por esse fato, em um futuro, inclusive próximo, esse turista poderá ser um importante prescritor do destino. Desta forma, 
entender as suas necessidades e os seus gostos torna-se uma ferramenta necessária para evitar que o mesmo volte ao seu lugar de origem insatisfeito, passando uma má imagem a outros potenciais turistas.

Com relação aos aspectos cognitivos e afetivos da imagem, encontrou-se que os turistas acadêmicos estão satisfeitos com Santiago de Compostela. Assim, uma imagem positiva se forma na sua mente, perpetrada tanto pelas emoções como pelos usos dos atributos tangiveis. Além disso, com essa satisfação, que depende da relação entre a imagem prévia com a imagem encontrada in situ, pode-se afirmar que o turista volta às suas origens propício à fidelidade, recomendando ou inclusive pensando em retornar um dia ao destino.

A partir da análise das entrevistas, pôde-se perceber também que os estudantes de anos anteriores não devem ser sub-estimados como variável para o êxito do destino. Como se verificou, quando decidiram levar a cabo essa experiência, os futuros estudantes se informaram sobre o destino escolhido e, dentre outras fontes de informação, os alunos de anos anteriores foram geralmente consultados. Portanto, uma experiência positiva pode ser quem de gerar recomendações a pessoas que lhes peçam informações.

Assim sendo, apresentadas também as fontes de informação utilizadas por esse coletivo, cabe destacar a importância de analisar o seu uso pelos mesmos. Desta maneria, tanto destinos como universidades, poderão direcionar as suas forças para gerar mais interação com esses turistas. Isto é, sabendo três aspectos relacionado com esta teoria. Primeiro, que no processo de formação da imagem do destino as fontes orgânicas são das consideradas mais fiáveis. Segundo, que potenciais turistas consultam indivíduos que já estiveram no destino anos anteriores para informar-se da experiência. E terceiro, que para buscar informação sobre o lugar a onde vão realizar seus estudos, os turistas acadêmicos consultam internet, em diferentes partes e de distintas maneiras (blogs, páginas oficiais...).

Portanto, conseguir que o turista interaja na rede, deixando comentários, criando conteúdo nos seus perfis privados, compartilhando fotos e ou viências durante estão vivenciando sua experiência no lugar, é algo que tem que ser considerado. Por conseguinte, é um desafio que tanto administração (como entes de planificação turística) como as próprias universidades, gestores de alojamentos ou restaurantes (entes beneficiados pelo turismo acadêmico) sejam capazes de aumentar a utilização da internet por parte do visitante, dado que as palavras deles terão mais peso na consolidação da sua imagem como destino. Visto que ela, esta imagem orgânica, é mais confiável que qualquer outra imagem publicitária.

Já sobre a lealdade, ela guarda relação com a dimensão conativa da imagem, portanto, ela é um aspecto comportamental que não pode ser matematicamente considerada. Neste caso, mesmo que os turistas pareçam estar mais inclinados à lealdade, não se podem esquecer os matizes e titubeos nas respostas, além de ser impossivel quantificar essa dimensão.

Também, conclue-se que é necessário considerar que uma das principais variáveis do fluxo turístico em um destino é a sua imagem, pois ela é a responsável de despertar no turista o desejo de o conhecer. Quanto mais positiva seja a sua imagem prévia, mais capacidade de atração terá este para possíveis turistas. O que se abstrae desta afirmação é que, no processo de decisão de eleição de um destino turístico pelo consumidor turístico, a imagem representa um fator preponderante para a escolha (HOLLOWAY, 2004; MIDDLETON et al., 2009).

Assim, a imagem do destino de turismo acadêmico deve ser o mais atinada à sua realidade, dado que desta maneira se assegura um acerto no público a que vai dirigida. No caso desta pesquisa, os (estudantes) turistas acadêmicos, pois estes buscam destinos com 
uma imagem que se enquadre no seu perfil. Assim, ao definir-se claramente a imagem, garante-se uma experiência mais verdadeira para o visitante, dando, à sua vez, maior possibilidade de éxito ao destino.

Recomenda-se estudar tanto o comportamento do turista acadêmico, como o impacto que este novo tipo de turismo tem para os destinos. Deste jeito, recomenda-se montar uma ferramenta estatística tipo survey para delimitar a imagem do destino de turismo acadêmico, e, considera-se que este atual estudo foi quem de fornecer variáveis fiáveis para a sua realização. Para essa futura linha de pesquisa, considera-se importante utilizar os atributos acadêmicos do destino para encontrar chaves para a fidelização dos turistas.

\section{REFERÊNCIAS}

Acerenza, M. A. (2002). Administração do turismo. São Paulo: HUCITEC.

Andrade Suárez, M. J. (2010). Modelo para la identificación de la imagen del turismo rural: tecnica estructurada y no estructurada. Revista de Análisis Turístico, Espanha, 9, 7493, xan./xul.

Andrade Suárez, M. J. (2011). The impact of secondary information sources on the formation of the tourist image: the case of rural tourism in Galicia. European Journal of Tourism, Hospitality and Recreation, Portugal, 2(1), 72-94.

Azevedo, A., Magalhães, D., Pereira, J. (2010). City Marketing. Myplace in XXI. Porto: Vida Económica.

Baloglu, S., McCleary, K. W. (1999). A model of destination image formation. Annals of Tourism Research, 26(4), 868-897.

Bauer, M. W. (2002). "Análise de Conteúdo Clássica: uma revisão.", em Pesquisa Qualitativa com texto, imagem e som: um manual prático. Petrópolis: Vozes, pp. 180-217.

Bignami, R. (2002). A imagem do Brasil no turismo: construções, dessafios e vantagem competitiva. São Paulo: Aleph.

Chon, K. S. (1991). Tourism destination image modification process: Marketing implications. Tourism Management, 12(1), 68-72, mar.

Couceiro, S. C., Paiva, G. F. A. V. "Patrimônio, identidade e Turismo: representações das camadas populares sobre patrimônio histórico da cidade de Olinda, Pernambuco (Brasil)". Congresso Turismo Cultural, Territórios e Identidades, Leiria.

Creswell, J. W., Clark, V. L. P. (2013). Pesquisa de Métodos Mistos. 2 ed. Porto Alegre: Penso.

Crespi Vallbona, M., Domínguez Pérez, M. (2013). Urban strategies in tourist places. Cases of Madrid and Barcelona, ROTUR, Revista de Ocio y Turismo, 6, 13-33.

Del Rincón, D., Arnal, J., Latorre, A., Sans, A. (1995). Técnicas de pesquisa en ciencias sociales. Madrid: Dykinson.

Echtner, C. M., Ritchie, J. R. B. (1991). The meaning and measurement of destination image. The Journal of Tourism Studies, 2(2), 2-12. 
Gândara, J. M. G. (2008). A imagem dos destinos turísticos urbanos. Revista Eletrônica de Turismo Cultural, número especial, 1-22, out.

García, E. A., Collado, A. M. (2007). La ensenhanza del espanhol como recurso turístico en Castilla-La Mancha. Boletín Económico de ICE, n. 2923, pp. 33-40, out.

García Espinoza, L. (2010). Contribuciones de las mujeres a la economía Rural y Acesso a los Recursos Productivos: Una Mirada desde los casos del Cantón Santa Elena (Provincia Santa Elena, Ecuador) y la Comarca de Lugo (Provincia Lugo, Espanha). 2010. 280f. Tese (Doctorado en Ingeniería Agroforestal). Universidade de Santiago de Compostela, Santiago de Compostela.

Gartner, W. C. (1993). Image Formation Process. Journal of Travel \& Tourism Marketing, 2, 191-215.

Huang, J. H., Cai, L. A. (2011). Destination choice model for transitional travel: College students in China. Tourism Management, 32, 697-699.

Janeiro, C., Tagliorette, A. [2007 ou 2008]. Perfil y satisfação del turista de avistaje de ballenas embarcado y costero en Puerta Pirámedes y El Doradillo. Valdés: Fundación Patagonia Natural.

Kim, J. H. (2014). The antecedents of memorable tourism experiences: The development of a scale to measure the destination attributes associated with memorable experiences. Tourism Management, 44, 34-45.

Kotler, P. et. al. (2005). Marketing de lugares. São Paulo: Prentice Hall.

Leiva, F. S. (2012). La movilidad estudiantil internacional como turismo acadêmico. Caracterización de la movilidad estudiantil y análisis de sus desplazamientos (flujos) turísticos durante su estadia en la Región Universitária de Valparaíso, una oportunidad no gestionada. Revista Geográfica Valparaíso, Chile, 46, 54-68.

Machado, D. F. C. (2010). A imagem do destino turístico, na percepção dos atores do trade turístico. Um estudo na cidade histórica de diamantina. 2010. Disertación (Mestrado en Administración) - Centro de Pós-Graduação e Pesquisas em Administração, Universidade Federal de Minas Gerais, Belo Horizonte.

Mariani, M. A. P., Barboza, M. M., Arruda, D. O. (2012). Elementos determinantes de la satisfação del consumidor de servicios turísticos. Estudios y perspectivas en turismo, 21(5), Ciudad Autónoma de Buenos Aires.

Ministério de Turismo, Secretaria Nacional de Políticas do Turismo. (2008). Turismo de estudos e intercâmbio: Orientações Básicas. Brassimlia.

Navarro, P., Díaz, C. (1994). "Análisis de Contenido", em Métodos y técnicas qualitativas de pesquisa en ciencias sociales. Madrid: Sintesis, pp. 177-223.

OMT Organización Mundial del Turismo. (2010). Introducción al turismo. Madrid.

Pawlowska, E. (2011). El turismo acadêmico. Un análisis económico para el caso de Galicia. 2011. 275f. Tese (Doutorado en Economia Aplicada). Universidade de Santiago de Compostela, Santiago de Compostela.

Pawlowska, E.; Martínez, F. (2009). Una aproximación ao impacto económico directo do turismo acadêmico: o caso dos intercambios Erasmus na Universidade de Santiago de Compostela. Revista Galega de Economia, 18(2), 91-110. 
Poupart, J. (2008). "A entrevista de tipo qualitativo: considerações epistemológicas, teóricas e metodológicas”, em A Pesquisa qualitativa: enfoques epistemológicos e metodológicos. Petrópolis: Vozes, pp. 215-253.

Rego, W. L., Pinzani, A. (2013). Vozes do Bolsa Família: Autonomia, dinheiro e cidadania. São Paulo: Unesp.

Salgado, M., Godinho, A., Milheiro, E. (2012). Informação Turística: DMC Turismo Serra da Estrela. Tourism \& Management Studies, 8, 88-98.

Samaja, J. (2012). Epistemología y metodología. Elementos para una teoria de la pesquisa científica. Buenos Aires: Eudeba.

Sancho Perez, A. et al. (2001). Apuntes de Metodología de la pesquisa en Turismo. Madrid: OMT.

Schiffman, L. G., Kanuk, L. L. (2000). Comportamento do consumidor. 6 ed. Rio de Janeiro: Livros Técnicos e Científicos Editora S.A.

Soares, J. R. R. (2015). "Relación entre imaxe turística construída e lealdade: Análise dos estudantes internacionais en Galicia". 2015. 311f. Tese (Doutorado em Direção e Planificação do Turismo) - Universidade da Coruña, A Coruña.

Souza, E. C., Strehlau, S., Silva, D., Strehlau, V. I. (2014). "Imagem do brasil: similaridades e diferenças na avaliação em dez países". Revista Eletrônica de Negócios Internaciomães, 9, 59-74.

Valles, M. S. (2014). Entrevistas qualitativas. Cuadernos Metodológicos. 2 ed., Madrid: Centro de Investigaciones Sociológicas.

Valls, J. F. (1992). La imagen de marca de los países. Madrid: McGraw-Hill.

Van Manen, M. (2003). Pesquisa educativa y experiência vivida. Ciencia humana para una pedagogía de la acción y la sensibilidad. Barcelona: Idea Books.

Vergara, S. C. (2005). Métodos de pesquisa em Administração. São Paulo: Atlas.

\section{HOW TO CITE THIS ARTICLE IN BIBLIOGRAPHIE}

Rodrigues Soares, J. R. (2015): "A contribuição das TICs para aumentar a credibilidade da imagem do destino. Estudo exploratório para o segmento de turismo acadêmico" Rotur. Revista de Ocio y Turismo, 9: 44-61, ISSN-e: 2695-6357, DOI: https:// doi.org/10.17979/rotur.2015.9.1.1340 